\title{
Peningkatan Kreativitas dan Produktivitas Kegiatan Membatik di Kelurahan Tlogomas Malang
}

\author{
Melany ${ }^{1}$, Anitarakhmi Handaratri ${ }^{2}$, Kestrilia Rega Prilianti ${ }^{3}$, Sultan Arif Rahmadianto ${ }^{4}$ \\ ${ }^{1}$ Program Studi Sastra Inggris Fakultas Bahasa dan Seni Universitas Ma Chung Malang \\ ${ }^{2}$ Program Studi Teknik Kimia Sekolah Tinggi Teknologi Industri Turen \\ ${ }^{3}$ Program Studi Teknik Informatika Fakultas Sains dan Teknologi Universitas Ma Chung Malang \\ ${ }^{4}$ Program Studi Desain Komunikasi Visual Fakultas Sains dan Teknologi Universitas Ma Chung Malang \\ melany.agustina@machung.ac.id
}

\begin{abstract}
Abstrak
Batik adalah salah satu warisan budaya Indonesia yang patut dilestarikan. Hampir di setiap wilayah Indonesia memiliki batik. Tidak hanya batik Jogja atau Solo yang namanya sudah mendunia, wilayah-wilayah lain di Indonesia juga memiliki batik. Saat ini komunitas membatik pada Keluarahan Tlogomas belum memiliki motif dan warna khusus yang menjadi ciri khas kota Malang. Oleh sebab itu, kegiatan pengabdian masyarakat ini bertujuan untuk memberikan pelatihan motif dan warna batik untuk memperkaya pola batik yang diproduksi. Dengan anggota komunitas yang tidak lebih dari 10 orang, usaha ini diharapkan dapat menjadi bibit kewirausahaan yang menghasilkan keuntungan. Tim pengabdian masyarakat memberikan sosialisasi, bantuan peralatan dan bahan, serta membuatkan akun khusus untuk membantu memperkenalkan dan memasarkan batik Tlogomas Selain itu, kegiatan ini juga untuk menjaga warisan budaya melalui peningkatan kreativitas dan produktivitas kegiatan membatik.
\end{abstract}

Kata-kata kunci : batik, Tlogomas, motif, warna, Malang

\section{Abstract}

Batik is one of Indonesian culture heritage that should be preserved.In almost every Indonesia region has batik.Not only batik Jogja or Solo whose name is s become incredibly global, other areas in Indonesia also has batik.Recently, 'membatik' community in Kelurahan Tlogomas do not have pattern and a special color which is feature of Malang city. Therefore, activities devotion to community aims to bring training motives and color batik to enrich batik pattern.With community members not more than 10 peoples, this work is hoped can be seeds entrepreneurship that produces advantage.Devotion to community' team provide socialization, assistance equipment and materials, and created special account to help introduce and markets batik Tlogomas. This activity is also to keep cultural heritage through the improvement of the creativity and productivity membatik activities.

Keywords : batik, Tlogomas, pattern, color, Malang

\section{Pendahuluan}

Batik merupakan warisan budaya yang tinggi nilainya dan memiliki sejarah panjang di Indonesia. Seni membatik kuno diawali dari keraton Solo dan Jogyakarta dimana saat itu hanya keluarga keraton saja yang boleh mengenakan batik. Motif-motif batik erat kaitannya dengan falsafah Jawa, misalnya : motif udan liris mengandung makna dalam menjalani kehidupan manusia diharapkan selalu tabah dan kuat menahan godaan dan tantangan serta tidak mudah mengeluh, motif parangkusumo mengandung makna bahwa setiap manusia yang mencari hakekat kehidupan harus dilandasi dengan perjuangan untuk mencari keharuman lahir dan batin, motif parikesit mengandung arti bahwa untuk menjalani kehidupan ini harus dengan kerja keras dan gesit tetapi tetap menjunjung tinggi norma-norma yang berlaku di masyarakat, dan masih banyak motif batik lain yang sangat terkenal dan dipakai sebagai simbol-simbol tertentu di masyarakat [1] .

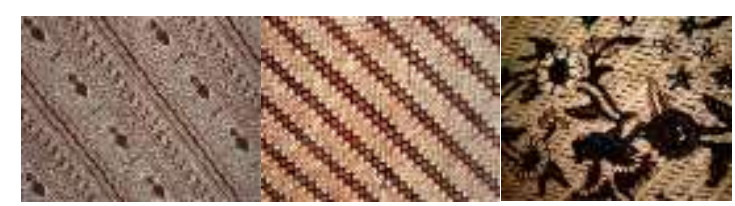

Gambar 1. Berbagai motif batik (udan liris, parangkusumo, parikesit)

Kecintaan masyatakat Indonesia terhadap batik bertambah dengan diakuinya batik Indonesia sebagai Warisan Kemanusiaan untuk Budaya Lisan dan nonbendawi oleh UNESCO pada tanggal 2 Oktober 2009 [2]. Oleh karenanya pemerintah menetapkan tanggal tersebut sebagai hari batik nasional. Pemerintah menganjurkan agar pada tanggal itu seluruh instansi pemerintah dan swasta memakai kain batik sebagai busana nasional. Bahkan di beberapa instansi tertentu, setiap hari Jumat dianjurkan menggunakan baju batik. Selain itu untuk meningkatkan kecintaan masyarakat khususnya kaum muda terhadap batik, pemerintah melalui kelompok-kelompok masyarakat melakukan pembimbingan dan pendampingan kegiatan membatik 
itu. Bahkan di kalangan akademisi pun turut berperan dengan memberikan sumbangsih melalui penelitianpenelitian yang berkaitan dengan pewarna alami untuk batik dan teknik-teknik membantik yang dimodernisasi.

Salah satu kota yang memiliki kelompok-kelompok membatik adalah kota Malang, Jawa Timur. Suatu komunitas kecil membatik telah tumbuh di daerah kelurahan Tlogomas, Malang sejak satu tahun terakhir ini. Komunitas ini diinisiasi dengan tekad serta keinginan ibu-ibu di lingkungan tersebut untuk belajar dan menekuni kegiatan membatik. Antusias komunitas membatik di kelurahan Tlogomas terdiri dari ibu-ibu PKK dan remaja putri sangat tinggi, terutama keinginan untuk mengembangkan batik tradisional model jumputan khas Malang. Motif yang dikembangkan pada komunitas ini antara lain motif labu kendi, watu gong kinanthi, teratai, kupu-kupu, batik ikat, panen labu, dan desainnya kurang menarik. Kombinasi pewarnaan juga masih kreatif sehingga batik yang dihasilkan hanya menggunakan 2-3 warna saja. Padahal daya tarik kain batik salah satunya adalah kerumitan pada kombinasi warna dan penonjolan gradasi warna yang beraneka ragam. Peralatan yang ada memang masih sedikit, terutama untuk kompor, canting, wajan, lilin, pewarna alami, kain mori, mangkuk, kuas, sarung tangan dan meja.

Komunitas ini memang relatif baru dan masih memerlukan pendampingan dan bantuan peralatan. Selain itu, mitra juga kesulitan untuk melakukan promosi pemasaran. Saat ini, penjualan dilakukan antar anggota komunitas melalui kekerabatan dan kegiatan sosial di kampung. Permintaan sebatas pada lingkungan sekitar dan belum menjangkau masyarakat di luar komunitas serta masyarakat internal saja.

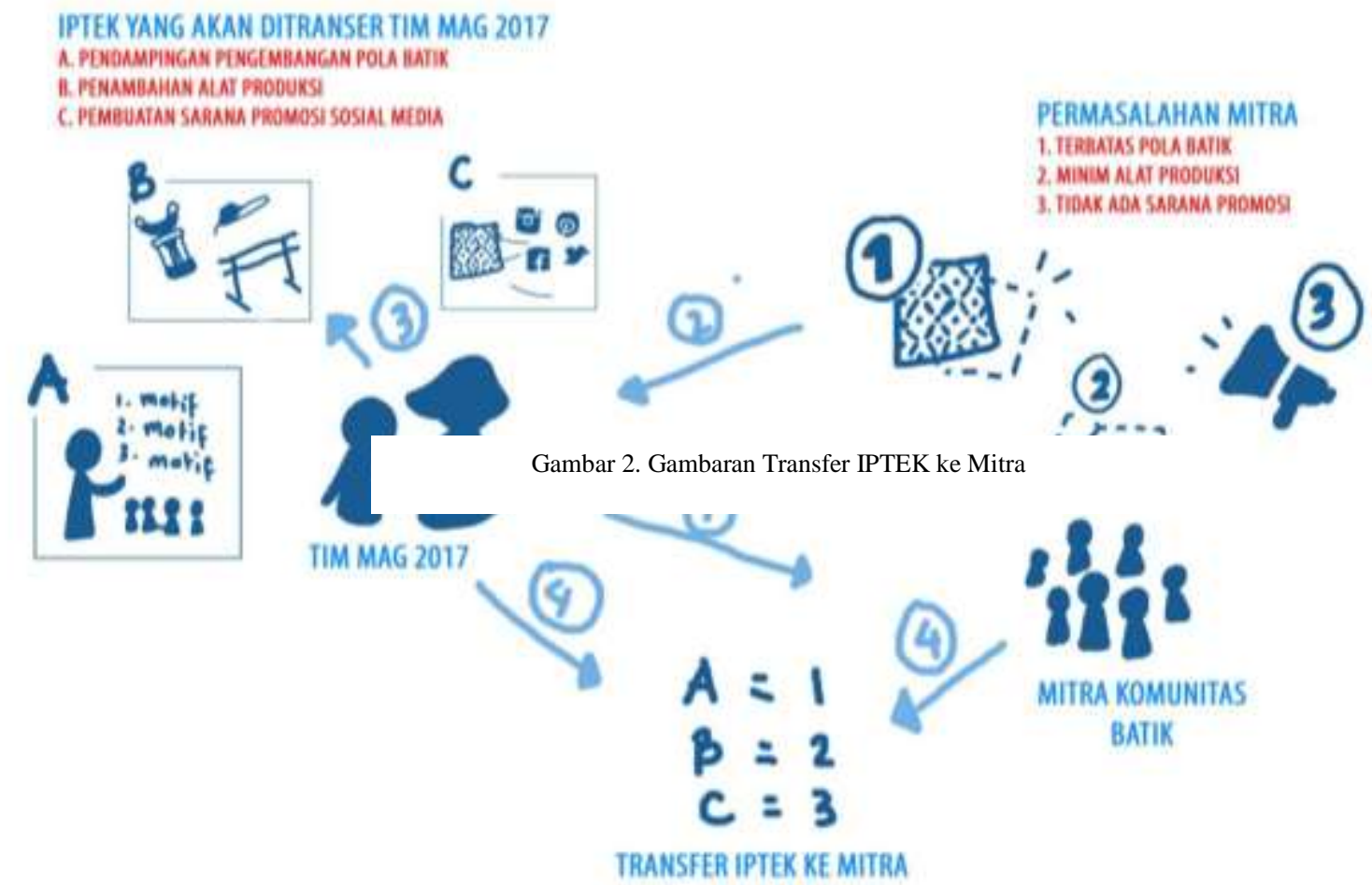

malangan eksotis. Semua motif ini khas daerah Malang dan keunikan dari kelurahan Tlogomas. Keunggulan lain hasil batik daerah ini adalah digunakannya pewarna alami seperti jenis kayu tinggi, jolawe, kayu nangka, indigo, atau daun tom. Pengerjaan membatik dilakukan dengan menyesuaikan pesanan konsumen karena prosesnya lama dan keterbatasan bahan baku.

\section{SUMBER INSPIRASI}

Tim pengabdi telah melakukan dialog dan diskusi dengan komunitas batik, Tlogomas, Malang sebagai mitra dan dapat diketahui permasalahan Komunitas Batik antara lain adalah : Motif-motif yang dikerjakan masih sangat sederhana dari segi desain dan struktur pola batik. Pengrajin masih fokus pada satu jenis pola/model dalam produk kain batik, sehingga

\section{Metode KegiataN}

Adanya identifikasi masalah - masalah tersebut kemudian ditawarkan solusi - solusi antara lain pelatihan pembuatan motif batik untuk memperkaya pola dan warna, pemberian peralatan berupa kompor untuk meningkatkan kuantitas produksi batik, dan sosialisasi melalui media sosial. Berdasarkan solusi solusi yang ditawarkan maka dilakukan langkah langkah kegiatan pengabdian masyarakat bagi komunitas batik di wilayah Kelurahan Tlogomas Malang. 
TABEL 1. METODE PENDEKATAN BERDASARKAN PERMASALAHAN

\begin{tabular}{|l|l|}
\hline \multicolumn{1}{|c|}{ Permasalahan } & \multicolumn{1}{c|}{ Metode Pendekatan } \\
\hline $\begin{array}{l}\text { Terbatasnya pola dan warna } \\
\text { batik }\end{array}$ & $\begin{array}{l}\text { Memberikan pelatihan } \\
\text { pembuatan motif batik } \\
\text { untuk memperkaya pola dan } \\
\text { warna }\end{array}$ \\
\hline $\begin{array}{l}\text { Minimnya peralatan penunjang } \\
\text { untuk mempercepat proses } \\
\text { pembuatan batik }\end{array}$ & $\begin{array}{l}\text { Memberikan satu unit } \\
\text { kompor untuk mempercepat } \\
\text { proses pembuatan batik }\end{array}$ \\
\hline & $\begin{array}{l}\text { Membuatkan akun pada } \\
\text { media sosial (instagram dan } \\
\text { pelum adanya sarana promosi } \\
\text { untuk menjual batik }\end{array}$ \\
& $\begin{array}{l}\text { promosi penjualan batik di } \\
\text { Malang }\end{array}$ \\
\hline
\end{tabular}

Dari tahapan kegiatan pada Tabel 1, tim pengabdi akan mengundang 5 orang dari komunitas untuk mengikuti pelatihan. Dari kegiatan tersebut, diharapkan ada 3-5 motif baru yang dapat dibuat. Selanjutnya, tim pengabdi akan menyerahkan satu unit kompor untuk mempercepat proses produksi batik. Sekaligus, tim pengabdi juga akan memberikan pendampingan sampai kain batik selesai diproduksi. Sedangkan untuk pembuatan akun media sosial serta bagaimana cara mengelolanya, tim pengabdi akan menunjuk satu orang dari komunitas sebagai admin dari media sosial yang akan dibuat.

Evaluasi pelaksanaan program pengabdian masyarakat ini dilakukan saat proses pendampingan dimana tim pengabdi bersama mitra akan meninjau kembali apakah motif dan warna yang telah ditentukan untuk diproses bisa diproduksi dan laku dijual di masyarakat melalui media sosial. Sedangkan keberlanjutan dilaksanakan dapat dilihat dari kemandirian mitra untuk terus memproduksi batik saat proses pendampingan sudah selesai serta bagaimana mitra memanfaatkan media sosial yang telah dibuat.

\section{KARYA UTAMA}

Langkah pertama dari tim abdimas adalah melakukan konsultasi dengan pihak Kelurahan Tlogomas untuk mengetahui perkembangan komunitas batik di lingkungan tersebut dan menyamakan persepsi atau program kegiatan. Selanjutnya dari pertemuan tersebut, tim abdimas diperkenalkan dengan perwakilan kelompok untuk membahas hal - hal sebagai berikut:

(1) Menganalisa motif batik yang ada di wilayah Tlogomas yaitu motif teratai, labu kendi, watu gong (warna emas), kinanti, piala dan kupu-kupu.

(2) Menganalisa kebutuhan mitra untuk meningkatkan kemampuan teknik membatik

(3) Menganalisa kebutuhan mitra untuk menambah motif sketsa batik dan diupayakan dapat menjadi ciri khas di wilayah Tlogomas

Motif yang ada kemudian dikembangkan melalui software untuk dibuat suatu pola. Pola tersebut diharapkan bisa menjadi suatu ciri khas dari batik Tlogomas.

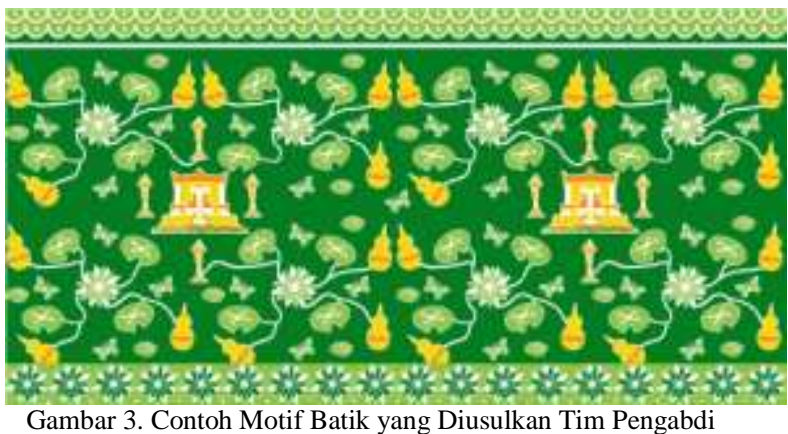

Pada motif batik yang diusulkan oleh tim pengabdi ada bentuk /pola yang diharapkan selalu muncul. Walaupun nantinya motif tersebut diubah warna dan posisi atau susunannya.

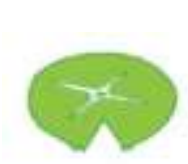

(a)

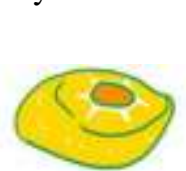

(b)

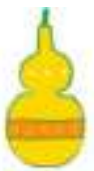

(c)

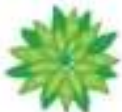

(d)

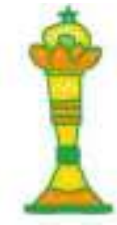

(e)

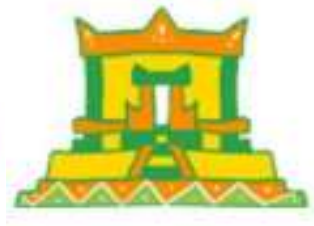

(g)
Gambar 4. Pola Khusus (a) Daun Teratai; (b) Watu Gong; (c) Labu Kendi; (e) Piala ; (f) Kupu - kupu; (g) Candi

Pola - pola khusus tersebut akan dikembangkan dan untuk melindungi kreativitas tersebut maka diperlukan suatu hak cipta. Selain itu adanya hak cipta ini tidak akan memberikan ruang kebebasan dalam berkreasi dan bersaing tanpa takut terjadi plagiasi [3].

Motif yang ada disosialisasikan pada setiap pertemuan.

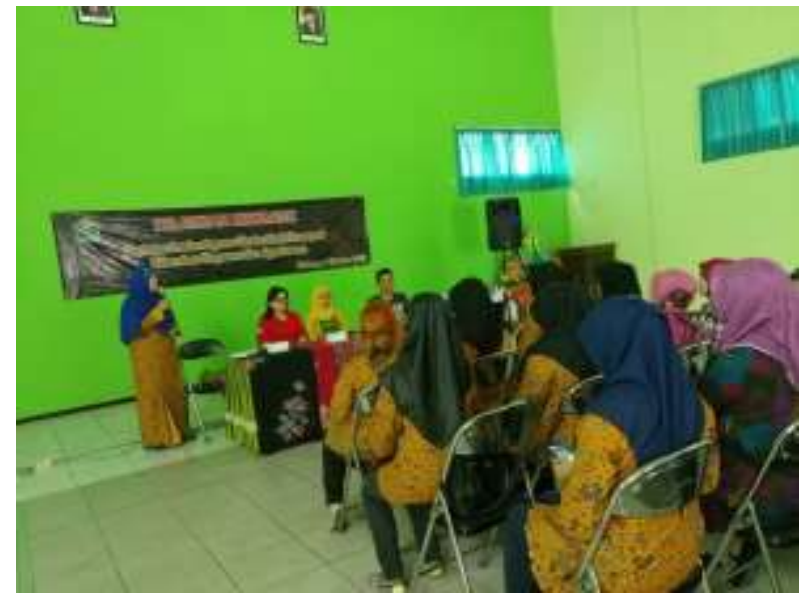

Gambar 5. Sosialisasi Motif Batik

Sosialisasi dilakukan di Keluarahan Tlogomas dan mengundang pakar batik di daerah Malang yaitu Bapak 
Suroso (Guru Ekstrakurikuler Membatik di SMK N 4, Malang).

Peralatan yang diberikan sesuai dengan kebutuhan antara lain canting, malam, kompor listrik, bahan pewarna, water glass dan kain polis. Peralatan peralatan tersebut digunakan secara bersama - sama. Kegiatan ini masih dalam tahap berlatih sehingga komposisi warna tidak ditentukan . Masing - masing individu bebas berkreasi tetapi pola yang digunakan sesuai dengan yang diberikan.

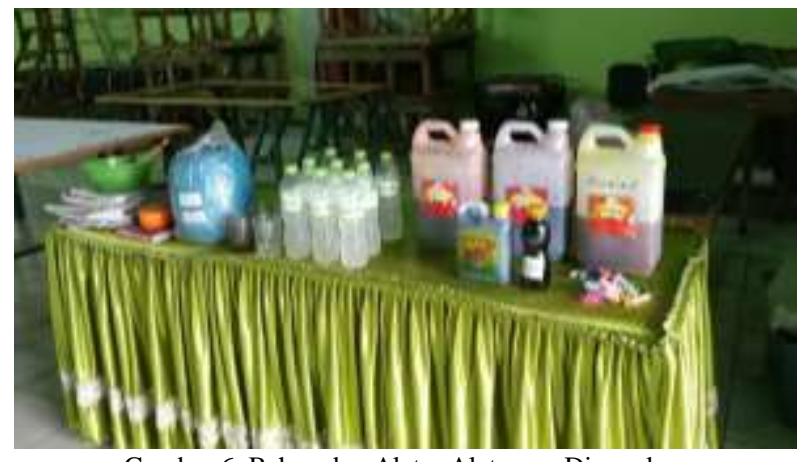

Gambar 6. Bahan dan Alat - Alat yang Digunakan

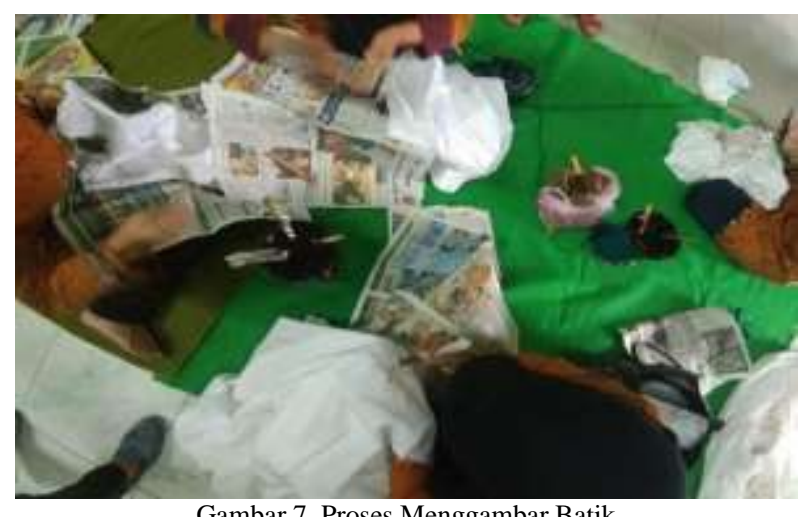

Gambar 7. Proses Menggambar Batik

Adanya kompor listrik memepercepat pelelehan malam dana menjaga suhu yang dibutuhkan.

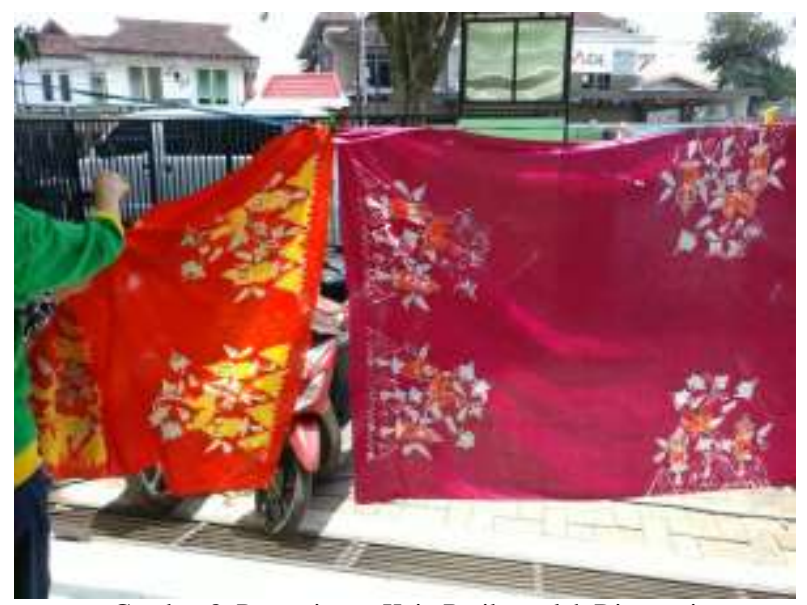

Gambar 8. Pengeringan Kain Batik setelah Diwarnai

Hasil pewarnaan tampak seperti Gambar 8 dapat diketahui bahwa pada saat kain masih basah dan pada saat kering terdapat perbedaan. Ketelatenan dalam menggambar dan mewarnai mempengaruhi kerapian gambar dan warna.

Pemecahan masalah pemasaran dan promosi maka pada kegiatan awal in, kain - kain batik yang bermutu bagus akan diperjualbelikan pada laman internet milik Kelurahan Tlogomas. Laman tersebut adalah www.etlogomas.com.

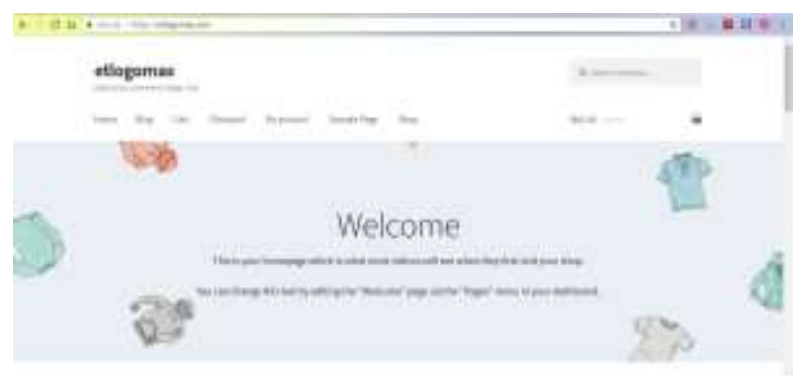

Gambar 9. Screenshot Beranda Laman Internet etlogomas.com

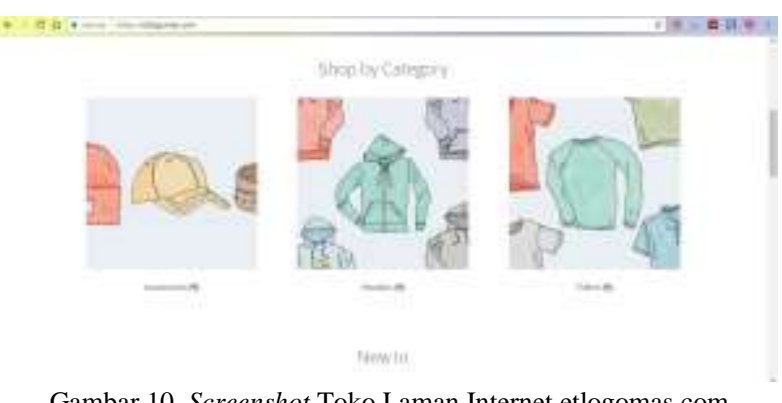

Model pemasaran yang lain sementara melalui media sosial anggota misalnya facebook dan instagram.

\section{ULASAN KARYA}

Beberapa hambatan dalam kegiatan ini adalah :

(1) Minimnya teknik membatik

Hal ini dikarenakan minimnya sumber daya pembatik yang sudah ahli. Hanya terdapat 2 orang yang sudah menguasai teknik membatik. Dan saat ini masih terus belajar untuk meningkatkan kemampuan membatik. Oleh sebab itu, tim Abdimas akan berupaya meningkatkan kemampuan teknik membatik.

(2) Minimnya motif batik

Motif batik yang selama ini dijadikan acuan dalam membatik masih terbatas. Diupayakan tim Abdimas akan memberikan beberapa sketsa motif dan warna batik khususnya juga yang dapat menjadi ciri dari wilayah Tlogomas.

(3) Waktu untuk berlatih membatik

Terbatasnya waktu dan tidak adanya jadwal berkala kegiatan membatik menjadi kendala untuk meningkatkan kemampuan membatik. Tim Abdimas akan berupaya membuat jadwal berkala sehingga produk batik dapat tersedia dan dijual secara online.

\section{KeSimpulan}

Kegiatan peningkatan kreativitas dan produktivitas membatik pada Kelurahan Tlogomas dimulai dari 
sosialisasi pola dan perbaikan teknik diikuti dengan pemberian bantuan peralatan dan bahan. Tim pengabdi juga membuatkan akun halaman khusus untuk media perkenalan pada masyarakat sekaligus memberikan peluang pemasaran secara daring. Metode ini merupakan langkah awal yang nantinya akan terus dikembangkan melalui teknik membatik lain seperti batik cap dan memperluas keanggotaan komunitas.

\section{DAMPAK DAN MANFAAT KEGIATAN}

Adanya kegiatan pengabidan membatik ini membantu meningkatkan teknik dan kemampuan komunitas dalam produksi kain batik dengan pola khusus daerah Tlogomas. Komunitas membatik di Kelurahan Tlogomas yang pada awalnya melaksanakan kegiatan ini hanya untuk mengisi waktu diajak untuk meningkatkan manfaat kegiatan agar produknya bernilai jual.

\section{Daftar PUStaka}

1. Adi Kusrianto. Batik : Filosofi, Motif \&amp; Kegunaan [Internet]. 2013 [cited 2017 Oct 18].
Available from:

http://openlibrary.telkomuniversity.ac.id/pustaka/65 685/batik-filosofi-motif-kegunaan.html

2. Bayu Galih. 2 Oktober 2009, UNESCO Akui Batik sebagai Warisan Dunia dari Indonesia Kompas.com [Internet]. KOMPAS. 2017 [cited 2017 Oct 18]. Available from: http://nasional.kompas.com/read/2017/10/02/08144 021/2-oktober-2009-unesco-akui-batik-sebagaiwarisan-dunia-dari-indonesia

3. Rahayu D. Perlindungan Hukum terhadap Hak Cipta Motif Batik Tanjungbumi Madura. Mimb Huk. 2010;23(1):1-236.

\section{Penghargane}

Terima kasih diberikan kepada pihak LPPM Universitas Ma Chung yang telah memberikan bantuan dana untuk pelaksanaan pengabdian masyarakat dalam program Ma Chung Abdimas Grant (MAG). 